\title{
Evaluation of Drop Size Distribution Impact on Rainfall Interception by Trees ${ }^{\dagger}$
}

\author{
Katarina Zabret ${ }^{1, *}$, Jože Rakovec ${ }^{2}$ and Mojca Šraj ${ }^{1}$ \\ 1 Faculty of Civil and Geodetic Engineering, University of Ljubljana, Jamova 2, SI-1000 Ljubljana, Slovenia; \\ mojca.sraj@fgg.uni-lj.si \\ 2 Faculty of Mathematics and Physics, University of Ljubljana, Jadranska 19, SI-1000 Ljubljana, Slovenia; \\ joze.rakovec@fmf.uni-lj.si \\ * Correspondence: katarina.zabret@fgg.uni-lj.si; Tel.: +386-1-42-54-052 \\ + Presented at the 2nd International Electronic Conference on Atmospheric Sciences, 16-31 July 2017; \\ Available online: http://sciforum.net/conference/ecas2017.
}

Published: 17 July 2017

\begin{abstract}
Not all precipitation, falling above the trees, reach the ground. Part of it is retained in the canopy and eventually evaporates back into the atmosphere. This is known as intercepted rainfall. The process is influenced by various meteorological parameters of which we have mainly focused on drop diameter and velocity. Rainfall in the open and throughfall under birch and pine trees have been measured since 2014 in Ljubljana, Slovenia. The results demonstrate that birch has intercepted $41 \%( \pm 32 \%)$ and pine $70 \%( \pm 24 \%)$ of rainfall on average per event. During the 146 individual events between 297 and 724,905 rain drops were recorded with the average drop diameter $0.73 \mathrm{~mm}( \pm 0.23$ $\mathrm{mm})$ and average drop velocity $3.71 \mathrm{~m} / \mathrm{s}( \pm 0.49 \mathrm{~m} / \mathrm{s})$. We have closely analyzed the effect of drop size and velocity on interception by pine during two rainfall events in June and July 2014. In June event drops with larger drop diameter $(6.5-8.5 \mathrm{~mm})$ were observed in the open causing an instant reduction of rainfall interception by pine for $30 \%$. Furthermore, twice during the both events the groups of drops with higher velocity $(7.6-10.4 \mathrm{~m} / \mathrm{s})$ were observed, causing the reduction in rainfall interception.
\end{abstract}

Keywords: rainfall; rainfall interception; throughfall; drop size distribution; drop diameter; drop velocity

\section{Introduction}

Rainfall interception can be observed when precipitation falls above the ground covered with vegetation. When rainfall reaches the tree canopy, some raindrops fall directly through the gaps in the canopy while the rest are retained on the leaves and branches. Drops retained in the canopy can later reach the ground by dripping or can evaporate back into the atmosphere. Latest is known as rainfall interception or interception loss. The precipitation that reaches the ground by dripping or falling directly through the gaps is named throughfall (Figure 1). Precipitation can also reach the ground as stemflow, water flowing down the branches and stem (Figure 1). 


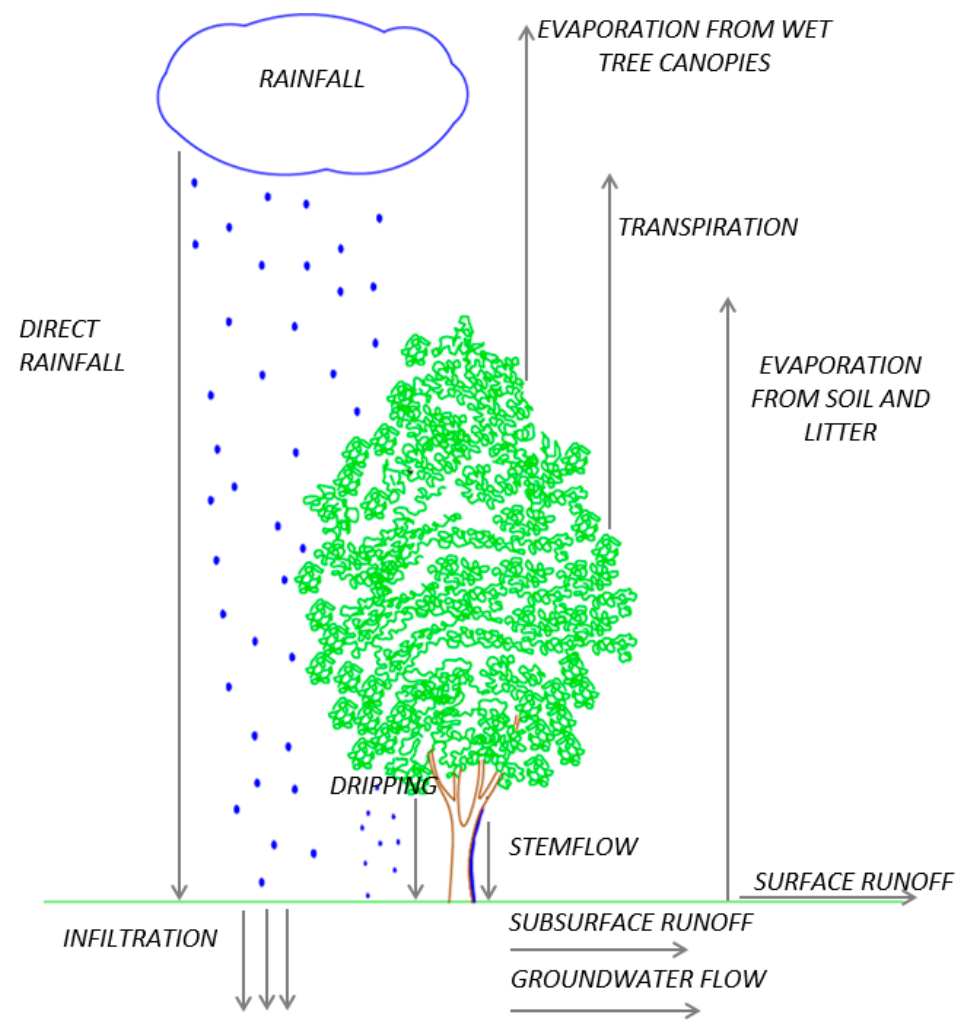

Figure 1. Hydrological cycle of rainfall interception.

The amount of intercepted rainfall is influenced by various parameters. In general they can be divided on vegetation and meteorological parameters. Some of the vegetation parameters are phenophase, canopy storage capacity, bark structure, leaf area index, diameter at breast height and canopy area [1]. Meteorological parameters are for example the amount of rainfall, the duration of rainfall event, rainfall intensity, wind velocity and direction, air temperature, humidity, rainfall type, and drop size distribution [2,3].They depend on geographical location and climate type. Their properties can change during the rainfall event.

Drop size distribution (spectrum) is a frequency distribution of drop diameters [4]. Velocity distribution is closely connected to it, as drop terminal velocity depends on its site $(v=v(D))$. Gunn and Kinzer [5] showed that velocity of the drops with diameter lower than $0.3 \mathrm{~mm}$ depends rather linearly on diameter and that the velocity of drops with diameter larger than $0.3 \mathrm{~mm}$ depends on the square root of diameter. Therefore velocity spectrum is in a great deal redundant with size spectrum. Both describes discrete nature of precipitation which is often neglected in research connected with rainfall [6]. Also the process of rainfall interception depends on rain drops with different properties $[7,8]$. So far the drop size distribution has been only indirectly analyzed in connection with rainfall interception. The focus was mainly set on the investigation of drop size distribution of the throughfall under the tree and its influence on the soil erosion [9-12]. Properties of the rainfall in the open were often overlooked. The main aim of the present study is to analyze the effect of the drop size distribution in the open on the amount of intercepted rainfall by trees.

\section{Methods}

\subsection{Description of the Experimental Setup}

The measurements were performed in the city of Ljubljana, Slovenia. The experimental site is located in an urban area of the city $\left(46.04^{\circ} \mathrm{N}, 14.49^{\circ} \mathrm{E}\right)$ at $292 \mathrm{~m}$ above the sea level. The climate is sub-alpine, with maritime influences from Mediterranean, and sub-continental from Panonian plane. Under the Köppen climate classification system it is categorized as CfB. The average annual 
temperature is $11^{\circ} \mathrm{C}$, ranging from $-5^{\circ} \mathrm{C}$ to $28^{\circ} \mathrm{C}$. The average annual rainfall is $1342 \mathrm{~mm}$, with the maximum monthly precipitation mainly recorded in autumn with a mean value of $260 \mathrm{~mm}$ [13].

The experimental site is flat and covers approximately $600 \mathrm{~m}^{2}$. Two groups of trees grow in the western part of the site. Throughfall and stemflow were measured under two black pines (Pinus nigra) and two birch trees (Betula pendula) (Figure 2). In the eastern part of the experimental site, where only the regularly cut low grass prevailed, the rainfall in the open (no-sheltered location) was measured. Drop size and velocity was measured on the rooftop of the nearby building.

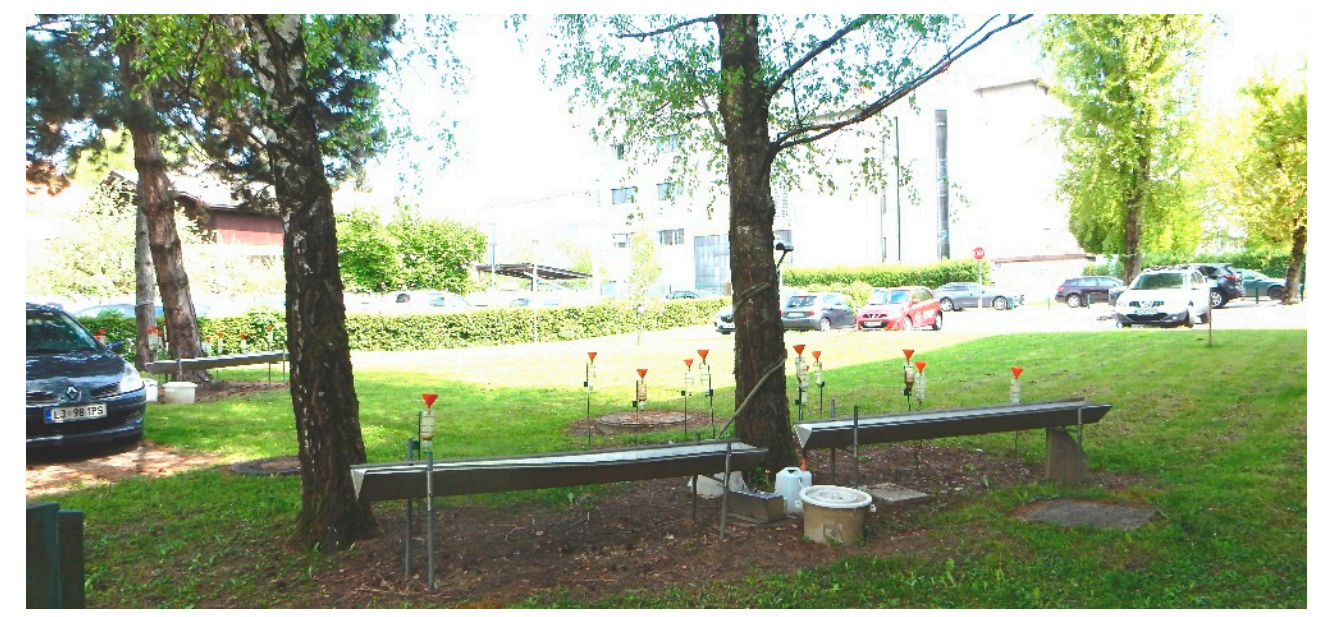

Figure 2. Experimental setup under the trees.

\subsection{Measurements}

Precipitation in the open area was measured with a tipping bucket $(0.2 \mathrm{~mm} /$ tip $)$ rain gauge (Onset RG2-M) with automatic data logger (Onset HOBO Event). It was positioned on the clearing at the experimental site. Near the experimental site there is a building, on roof top of which the OTT Parsivel optical disdrometer was placed. Its measuring area is $54 \mathrm{~cm}^{2}$. Measured data are allocated to one of the 32 drop size or velocity classes. In addition to drop diameter and velocity disdrometer also measures amount of precipitation, its intensity, number of particles (rain drops) and temperature.

Throughfall was measured under four trees (two pine and two birch trees). Under each of the selected type of trees various methods of throughfall measurements were implemented in order to catch the spatial variability of throughfall and to avoid missing data. Two steel trough gauges $(2.5 \times$ $0.3 \mathrm{~m}$ ) were positioned alongside each tree stem towards the tree canopy edge (Figure 2). Under each tree species one gauge was equipped with a tipping bucket flow gauge (Unidata 6506G) and an automatic data logger (Onset HOBO Event), automatically recording the data. The data from the other trough gauge, connected to a polyethylene $10 \mathrm{~L}$ containers attached to $50 \mathrm{~L}$ polyethylene barrel, was collected manually after each event. Additionally ten roving manually-read wedge gauges with $1 \mathrm{~L}$ capacity and $78.5 \mathrm{~cm}^{2}$ catch area were randomly placed underneath the trees.

Stemflow was measured for one tree of each species. A rubber collar was halved and spirally wrapped around the stem, attached with nails and silicone. The lower part of the hose was connected to a $20 \mathrm{~L}$ manually read polyethylene container, which was emptied at the same time as the throughfall gauges.

\subsection{Methods of Data Analysis}

The rainfall event was defined based on the time gap between the end of the previous and the beginning of the next rainfall event. There should be at least 4-h dry period between the events in which the canopy could dry out. For each event the number of drops, their diameter and velocity were obtained from the disdrometer's raw data. The average drop diameter and velocity per event were calculated and the number of rainfall drops was summed up. Stemflow was calculated based on the projected area of the corresponding tree canopy [14]. 
Rainfall interception (I) was defined based on a simple water balance equation using measured precipitation $(\mathrm{P})$, throughfall $(\mathrm{TF})$ and stemflow $(\mathrm{SF})$ e.g., [15]:

$$
\mathrm{I}=\mathrm{P}-\mathrm{TF}-\mathrm{SF} \text {. }
$$

Data analyses were performed using $\mathrm{R}$, a software environment for statistical computing and graphics [16].

\section{Results}

Since the beginning of the year 2014 the measurements of rainfall, throughfall and stemflow have been performed. The snow events were excluded. Until the 15 June 2016 there were 309 rainfall events observed with total amount of $3023.1 \mathrm{~mm}$ rainfall. In the detailed analysis we have taken into account 146 rainfall events from 1 January 2014 to 15 June 2016 for which the complete data on drop diameter and velocity were available. During these events $1442.7 \mathrm{~mm}$ of rainfall was measured.

\subsection{Throughfall, Stemflow and Rainfall Interception}

Throughfall under birch was equal to $7.2 \mathrm{~mm}( \pm 11.5 \mathrm{~mm})$ on average per event and in total accounted for $73 \%$ of rainfall (Figure 3). Throughfall under urban deciduous trees in Melbourne, Australia was measured at $71 \%$ under Eucalyptus saligna tree [14] which is similar to the results of present study. Furthermore, under the pine on average $5.3 \mathrm{~mm}( \pm 9.9 \mathrm{~mm})$ of throughfall was observed per event. In total throughfall under the pine resulted in $54 \%$ of rainfall. The results agree with throughfall reported by Asadian and Weiler [17] as it was equal to 50\% and $46 \%$ for Pseudotsuga menziesii and Thuja plicata, respectively. There were 23 events in which no throughfall was observed under birch and 30 events without throughfall under pine, mainly in cases of weak precipitation (all rainfall was intercepted).

Stemflow was much lower than throughfall (Figure 3). In total stemflow under birch was equal to $55.0 \mathrm{~mm}$ ( $4 \%$ of rainfall) while under pine it was negligible with sum of $0.9 \mathrm{~mm}$ ( $0.06 \%$ of rainfall). Stemflow was observed during 73 events in case of birch and ranged between $0.001 \mathrm{~mm}$ and 4.61 $\mathrm{mm}$. Under the pine it was detected during 60 rainfall events; however, the single event amount ranged up to only $0.12 \mathrm{~mm}$. The amount of stemflow highly depends on bark structure. Ilek and Kucza [18] measured coefficient of development of the interception surface of bark for eight tree species and showed that mean value of the coefficient is lower for birch (1.74) than for pine (1.83).

Rainfall interception by birch was on average equal to $41 \%( \pm 32 \%)$ per event, while pine has on average intercepted $70 \%( \pm 24 \%)$ per event (Figure 3). In two events birch has not intercepted any rainfall, in the case of pine, however, at least minimal interception was always observed.
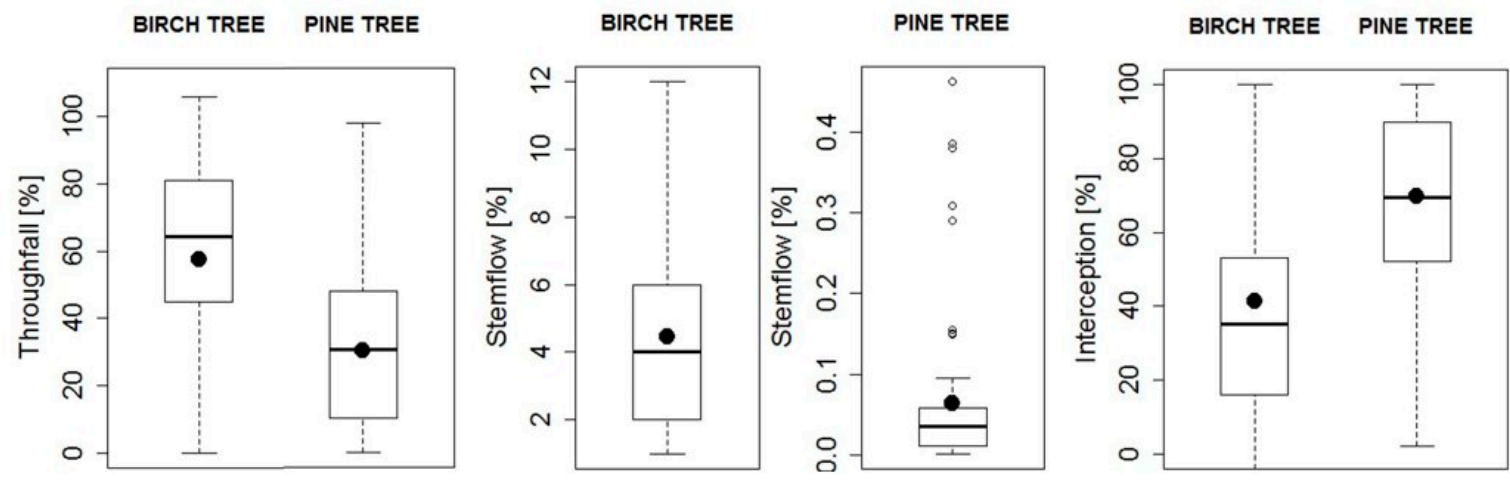

Figure 3. Box-and-whiskers plot of throughfall, stemflow and rainfall interception under birch and pine trees (note different scale for stemflow). 


\subsection{Number of Rainfall Drops, Their Diameter and Velocity}

The number of rainfall drops per event varied between 297 and 724,905. Less than 1000 drops were detected in 5 events, all of which delivered less than $0.4 \mathrm{~mm}$ of rainfall. The maximum number of raindrops was observed during an October 2015 event with $33.6 \mathrm{~mm}$ of rainfall. On average 85,893 of rainfall drops per event were observed.

Rain drop diameters were on average equal to $0.73 \mathrm{~mm}( \pm 0.23 \mathrm{~mm})$. The largest observed drop diameter during all measured events was equal to $24.5 \mathrm{~mm}$ while the smallest detected by the instrument was $0.312 \mathrm{~mm}$, observed in every event.

Average rain drop velocity ranged between $2.52 \mathrm{~m} / \mathrm{s}$ and $5.50 \mathrm{~m} / \mathrm{s}$ per event. The highest measured drop velocity was observed during 8 events and reached up to $17.6 \mathrm{~m} / \mathrm{s}$. The lowest velocity detected by the disdrometer was equal to $0.05 \mathrm{~m} / \mathrm{s}$ and was recorded in 44 events.

The effect of drop size and velocity on rainfall interception was closely analyzed for two selected rainfall events: 13 June 2014 and 3 July 2014. The events were selected according to their similar duration. In order to focus solely on the influence of drop size and velocity just throughfall data for pine tree were taken into account.

\section{Discussion}

\subsection{Effect of Drop Size Distribution on Rainfall Interception}

Taking into account all 146 rainfall events, the increasing trend of interception with larger drop diameters and velocity was observed (Figures 4 and 5). It is more obvious in case of the birch than of the pine. The rainfall interception by birch was more variable due to phenophases (leafed and leafless canopy). As the range of rainfall interception values was smaller for the pine (Figure 3), for which the trend was not that noticeable.

The results (Figure 4) indicate that interception was larger for events with larger average drop diameters. However this results should be critically interpreted. Large rainfall drops may be mostly intercepted at the beginning of the rainfall events when the canopy is not yet saturated. With the development of the event the canopy storage capacity is achieved and the interception decreases. The average rainfall duration of the events with the largest drop diameters $(>1.4 \mathrm{~mm})$ was $12 \mathrm{~min}$ while average rainfall duration of the events in all other three groups exceeds $2.5 \mathrm{~h}$. During the short rainfall events the canopy was not fully saturated. Taking this into account the results are similar to model simulation which show that small rain drop volume induces high interception losses $[2,7,19]$.
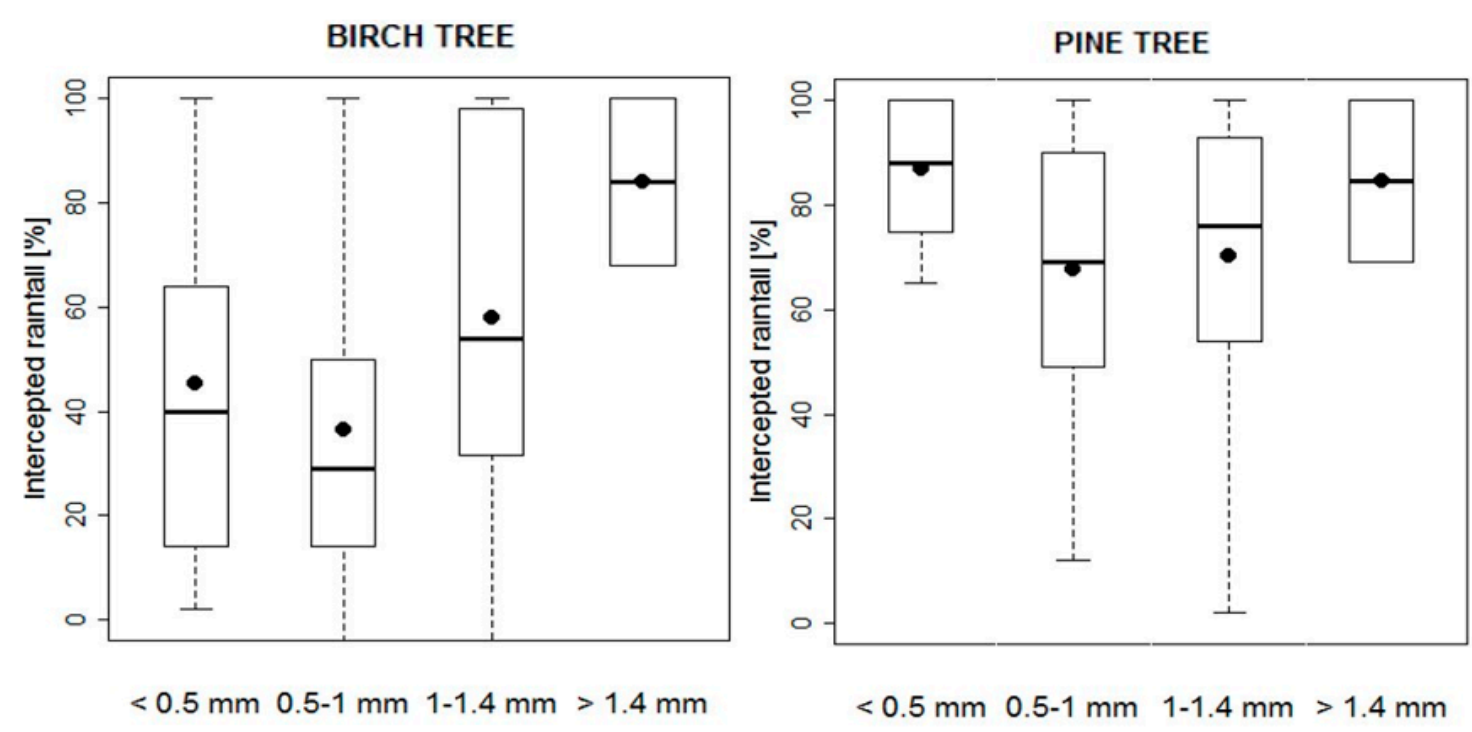

Figure 4. Box plots of rainfall interception according to average event's drop diameter classes. 
Similarly as with drop diameter, rainfall interception also increases with higher drop velocity (Figure 5). The first group of events with the lowest velocities $(<3 \mathrm{~m} / \mathrm{s})$ had small amounts of rainfall, on average $1.1 \mathrm{~mm}( \pm 1.23)$. For events in all the other groups average rainfall amount exceeds $10 \mathrm{~mm}$.

BIRCH TREE

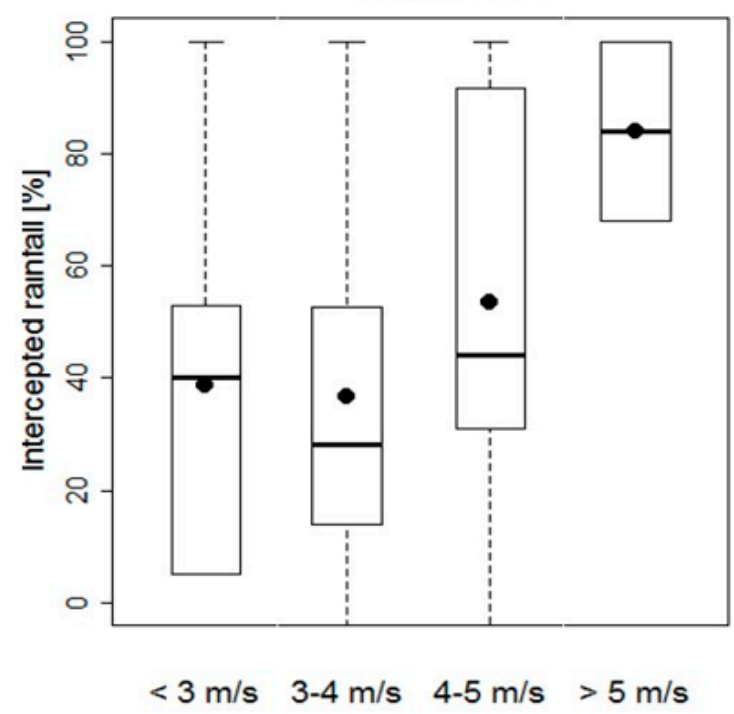

PINE TREE

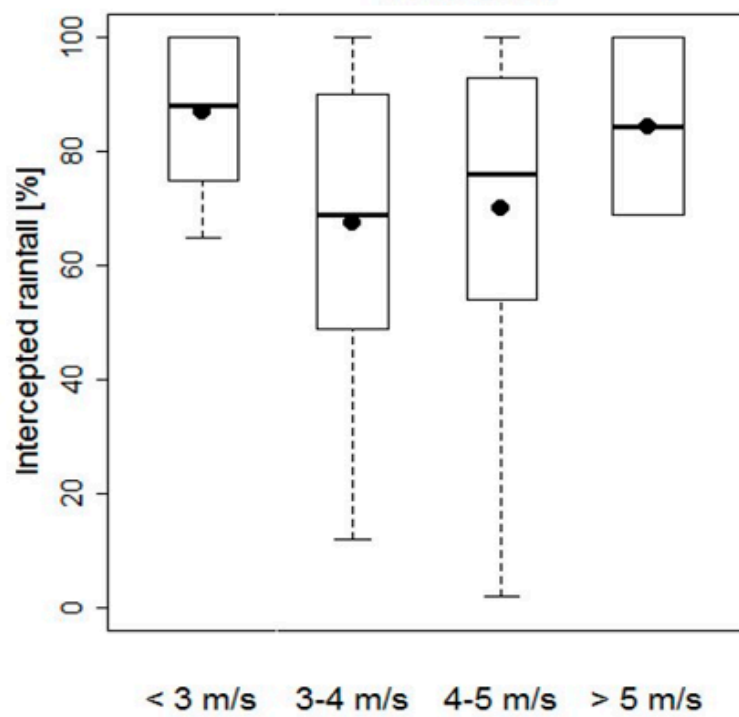

Figure 5. Box plot of rainfall interception according to average event's drop velocity classes.

The effect of rain drop diameter and velocity on rainfall interception depends also on other meteorological parameters which help to explain certain deviations from the main trends. Therefore the analysis should take into account also other parameters (e.g., rainfall amount, duration, intensity) or should be performed on the event scale.

\subsection{June and July 2014 Events}

The June event started at 8 PM and lasted for $75 \mathrm{~min}$. The total amount of rainfall observed during the event was $10.2 \mathrm{~mm}$ while throughfall under the pine resulted in $4.79 \mathrm{~mm}$. Pine intercepted $53 \%$ of rainfall. The event was characterized as heavy rainfall with short term intensity up to 0.36 $\mathrm{mm} / \mathrm{min}$. During the event 29,679 rainfall drops were detected with an average drop diameter of 1.11 $\mathrm{mm}( \pm 0.25 \mathrm{~mm})$ and average drop velocity of $4.45 \mathrm{~m} / \mathrm{s}( \pm 0.55 \mathrm{~m} / \mathrm{s})$.

The July event started later during the night, at 1:30 AM and lasted $72 \mathrm{~min}$. It was a moderate rainfall event with $5.6 \mathrm{~mm}$ of rainfall and $1.96 \mathrm{~mm}$ of throughfall under the pine. The rainfall interception by pine was $65 \%$. The short term intensity was lower, up to $0.2 \mathrm{~mm} / \mathrm{min}$. During the event 21,926 rainfall drops were detected with an average drop diameter of $1.20 \mathrm{~mm}( \pm 0.17 \mathrm{~mm})$ and average drop velocity of $4.61 \mathrm{~m} / \mathrm{s}( \pm 0.36 \mathrm{~m} / \mathrm{s})$.

\subsection{Effect of Drop Diameter on Rainfall Interception}

Average June event's drop diameter was smaller than for the July event. But singular drop diameters of some rainfall drops were larger for the June event. In this case the largest drop diameter observed was $8.5 \mathrm{~mm}$ while in July event it was equal to $5.5 \mathrm{~mm}$.

In June event throughfall started simultaneously with the rainfall (Figure 6). Throughfall was quite low and accounted for around 30\% of rainfall in the open. After 10 min concentration of the rainfall drops increased and after $15 \mathrm{~min}$ reached the largest drop diameter of $8.5 \mathrm{~mm}$. Accordingly throughfall increased to $50 \%$ and beyond. The large number of rainfall drops and large drop diameters in one moment induced throughfall larger than the rainfall (Figure 6). That means that we have measured more rainfall under the tree than in the open.

In the first half of the event, until 20:25, 70\% of total rainfall amount was measured. In the second part of the event constant throughfall above $40 \%$ can be observed due to the saturated tree canopy. 
After sixty minutes from the beginning of the event, at 20:55, another appearance of drops with larger diameters, reaching $4.25 \mathrm{~mm}$, was observed. Due to the saturation of the canopy the throughfall instantly increased and again exceeded rainfall in the open.

Similar phenomenon of higher amount of throughfall under the maize canopy than the amount of the rainfall in the open was also observed by Frasson and Krajewski [20]. In this case it was observed for drop diameters between $3.25 \mathrm{~mm}$ and $5.75 \mathrm{~mm}$.

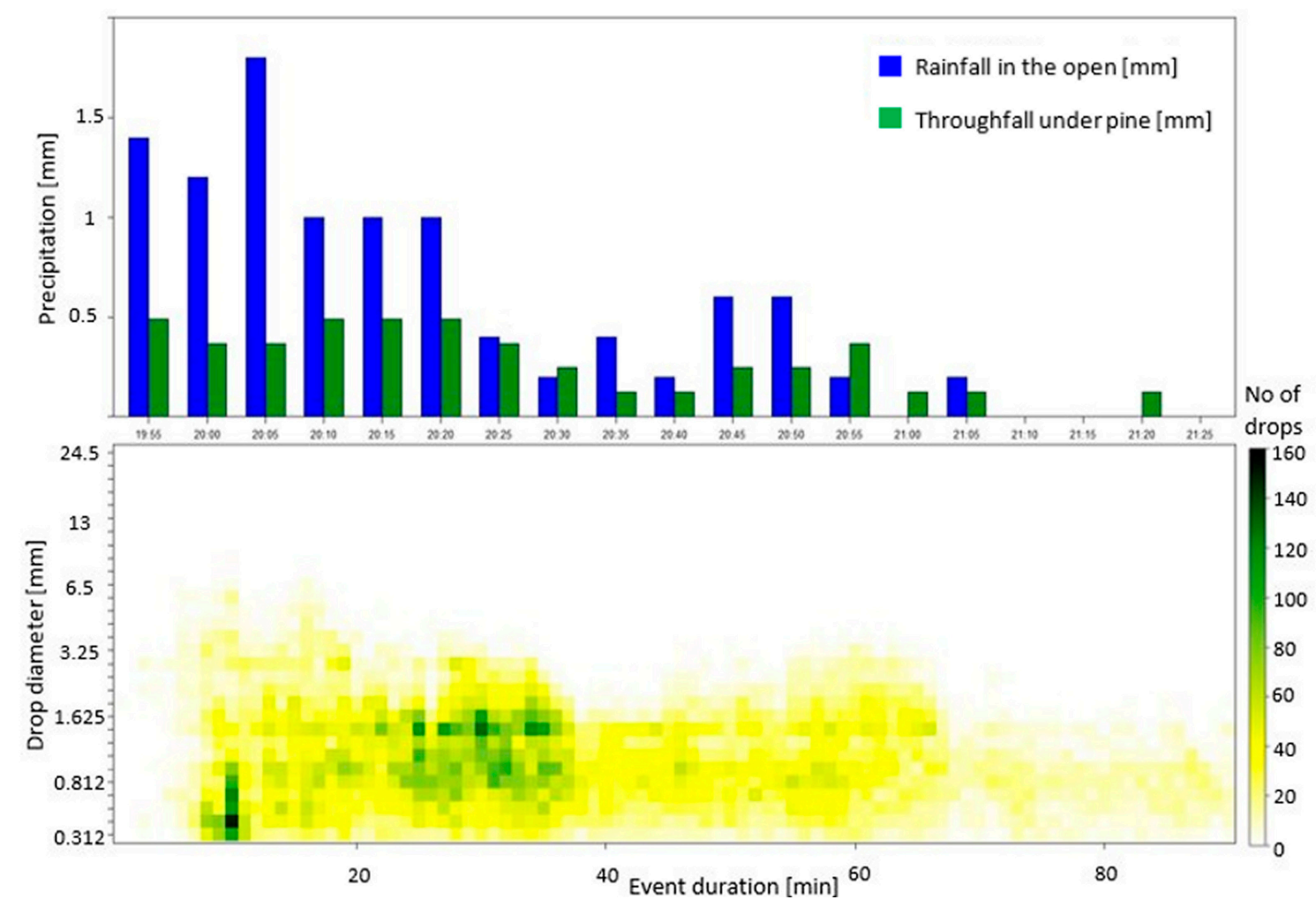

Figure 6. Rainfall and throughfall under the pine in 5-min time interval (upper panel) and drop size distribution in 1-min time interval (bottom panel) for the 13 June 2014 event.

In July event rainfall started gradually and only induced throughfall after $10 \mathrm{~min}$ (Figure 7). In first $40 \mathrm{~min}$ of the event only $32 \%$ of total rainfall amount was measured but the diameters of the drops were quite diverse as they varied between $0.312 \mathrm{~mm}$ and $5.5 \mathrm{~mm}$. Throughfall was insignificant until the 55th $\min$ (02:10), when larger number of drops occurred. This induced higher throughfall, namely between $40 \%$ and $60 \%$.

The highest drop diameter of July event was constant through the whole observation period. In this case neither increase in drop diameter nor larger drops were observed comparing to the previous event. Although the higher concentration of drops increased the troughfall, it did not exceed more than $60 \%$ of the rainfall and never exceed amount of the rainfall in the open as in previous event.

Rain drop diameter significantly influences throughfall under the pine tree. For larger rainfall drop diameters throughfall under the tree exceeds rainfall amount in the open. The time lag of the response depends on the saturation of the tree canopy. However also the maximum canopy storage depends on drop size [19]. Constant structure of rain drop diameters without the increase of drop diameter effects throughfall amount due to the number of drops; however, no exceptional increases were observed. 


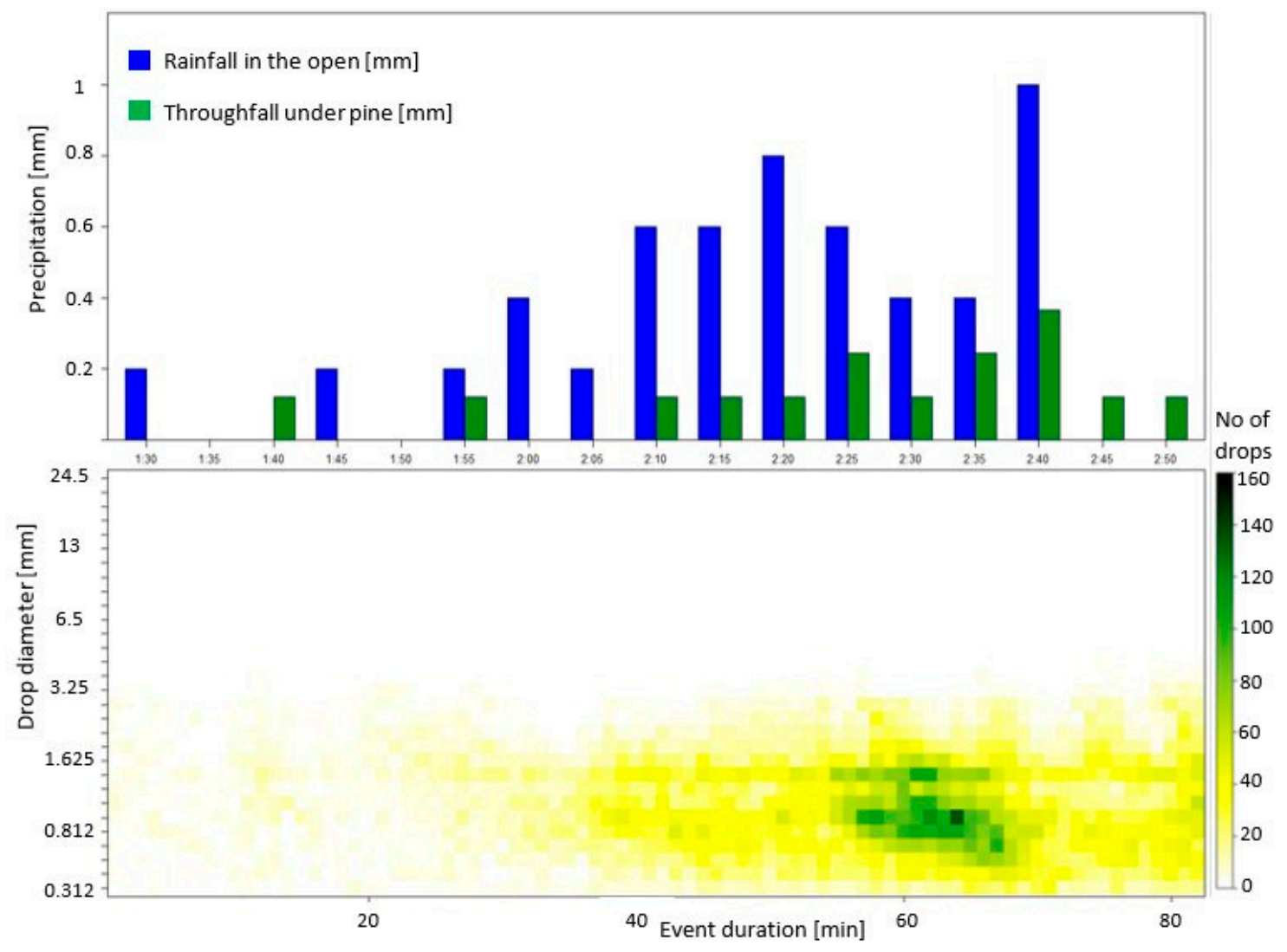

Figure 7. Rainfall and throughfall under the pine in 5-min time interval (upper panel) and drop-size distribution in 1-min time interval (bottom panel) for the 3 July 2014 event.

\subsection{Effect of Drop Velocity on Rainfall Interception}

Rain drop velocities ranged between $0.05 \mathrm{~m} / \mathrm{s}$ and $13.6 \mathrm{~m} / \mathrm{s}$ in June event and between $0.05 \mathrm{~m} / \mathrm{s}$ and $10.4 \mathrm{~m} / \mathrm{s}$ in July event. Although the single rain drops reached higher velocities during the June event, the average rain drop velocity was higher for July event. According to the relationship between the drop diameter and velocity [5] the influence of the drop velocity on the throughfall is similar to the influence of the drop diameter.

The rain drop velocities in the June event were quite low in the first $5 \mathrm{~min}$ but soon reached up to maximum values. At the same point the throughfall increased from less than $30 \%$ to almost $50 \%$ of rainfall and eventually exceeded the rainfall in the open. Another group of the drops with high velocities was observed $60 \mathrm{~min}$ from the beginning of the event. In this case the exceedance of throughfall according to the rainfall was immediate.

The increase of throughfall under the maize canopy in comparison to the rainfall in the open was reported by Frasson and Krajewski [20] due to larger drop diameters and also higher drop velocities. Drop velocities estimated to induce higher throughfall were ranging from $1.4 \mathrm{~m} / \mathrm{s}$ to $5 \mathrm{~m} / \mathrm{s}$.

In the July event the velocity of rain drops was similar to the average value almost for the whole hour. Only around $50 \mathrm{~min}$ from the beginning of the event the extension of the drop velocity spectrum can be observed. This change in the drop velocity caused the increase of throughfall from around $20 \%$ up to $61 \%$.

In the July event the effect of rain drop velocities is not that evident as the effect of rain drop diameter. In the June event the first observed throughfall higher than the rainfall occurs 25 min after the observed drops with high velocity. It was probably not triggered only by the high velocity of the drops but also by the high number of the rain drops. However, the fully saturated tree canopy seems to react differently to the change in structure of the drop velocities. In the June event the second highvelocity group of drops caused an instant increase of throughfall. 


\section{Conclusions}

Rainfall interception is an important part of the hydrological cycle, effecting amount of discharge in the rivers, intensity of erosion in forests and amount of surface runoff in the urban areas. It is influenced by various meteorological and vegetation parameters. Each of the parameters has to be analyzed on its own to better understand its effect on the throughfall and stemflow. Additionally, in the interpretation of the single parameter effect, also other aspects should be kept in mind.

Analysis of the effect of an event's average drop diameter and velocity on rainfall interception for 146 events suggests, that higher average drop diameters and drop velocities induces higher event's rainfall interception. But we have to take into account decrease of rainfall interception with development of the rainfall event. At the beginning rainfall interception is usually higher due to dry canopy and decreases during the event when the canopy gets saturated. Detailed analysis of a single development phases of a rainfall event could enable more reliable insight into effect of rain drop diameter and velocity on rainfall interception.

Detailed data during the event showed that increase of the drop diameter or velocity values caused higher throughfall, which means lower rainfall interception. In this comparison influence of other parameters is evident. Event with higher rainfall amount (e.g., June event) has in general lower rainfall interception due to the saturation of the canopy. Analysis of an event time series data showed that rain drop velocity and diameter significantly effects throughfall under the pine tree. In some cases increase in drop velocity or diameter spectra even induced throughfall larger than the rainfall in the open. The response rate of the throughfall to larger or faster drops seems to base on the saturation of the tree canopy. To confirm this effect, detailed analysis of additional events are necessary.

Conflicts of Interest: The authors declare no conflict of interest

\section{References}

1. Zabret, K. The influence of tree characteristics on rainfall interception. Acta Hydrotech. 2013, 26, 99-116.

2. Crockford, R.H.; Richardson, D.P. Partitioning of rainfall into throughfall, stemflow and interception: Effect of forest type, ground cover and climate. Hydrol. Process. 2000, 14, 2903-2920, doi:10.1002/10991085(200011/12).

3. Šraj, M.; Brilly, M.; Mikoš, M. Rainfall interception by two deciduous Mediterranean forests of contrasting stature in Slovenia. Agric. For. Meteorol. 2008, 148, 121-134, doi:10.1016/j.agrformet.2007.09.007.

4. American Meteorological Society (AMS). Glossary of Meteorology. Available online: http://glossary.ametsoc.org/wiki/Drop-size_distribution (accessed on 18 May 2017).

5. Gunn, R.; Kinzer, G.D. The Terminal Fall Velocity for Water Droplets in Stagnant Air. J. Atmos. Sci. 1949, 6, 243-248.

6. Uijlenhoet, R.; Sempere Torres, D. Measurement and parameterization of rainfall microstructure. J. Hydrol. 2006, 328, 1-7, doi:10.1016/j.jhydrol.2005.11.038.

7. Calder, I.R. Dependence of rainfall interception on drop size: 1. Development of the two-layer stochastic model. J. Hydrol. 1996, 185, 363-378, doi:10.1016/0022-1694(95)02998-2.

8. Hall, R.L. Interception loss as a function of rainfall and forest types: Stochastic modelling for tropical canopies revisited. J. Hydrol. 2003, 280, 1-12, doi:10.1016/S0022-1694(03)00076-3.

9. Nanko, K.; Hotta, N.; Suzuki, M. Evaluating the influence of canopy species and meteorological factors on throughfall drop size distribution. J. Hydrol. 2006, 329, 422-431, doi:10.1016/j.jhydrol.2006.02.036.

10. Nanko, K.; Mizugaki, S.; Onda, Y. Estimation of soil splash detachment rates on the forest floor of an unmanaged Japanese cypress plantation based on field measurements of throughfall drop sizes and velocities. Catena 2008, 72, 348-361, doi:10.1016/j.catena.2007.07.002.

11. Nanko, K.; Ondab, Y.; Ito, A.; Moriwakic, H. Spatial variability of throughfall under a single tree: Experimental study of rainfall amount, raindrops, and kinetic energy. Agric. For. Meteorol. 2011, 151, 11731182, doi:10.1016/j.agrformet.2011.04.006.

12. Bassette, C.; Bussiere, F. Partitioning of splash and storage during raindrop impacts on banana leaves. Agric. For. Meteorol. 2008, 148, 991-1004, doi:10.1016/j.agrformet.2008.01.016. 
13. ARSO: Podnebne Razmere v Sloveniji (The Climatic Conditions in Slovenia). Available online: http://www.arso.gov.si/vreme/podnebje/podnebne_razmere_Slo71_00.pdf (accessed on 17 May 2015).

14. Livesley, S.J.; Baudinette, B.; Glover, D. Rainfall interception and stemflow by eucalypt street trees-The impacts of canopy density and bark type. Urban For. Urban Green. 2014, 13, 192-197, doi:10.1016/j.ufug.2013.09.001.

15. Šraj, M. Intercepted precipitation: Measurements and analysis. Geogr. Vestnik 2008, 81, 99-111.

16. R Core Team. R: A Language and Environment for Statistical Computing; R Foundation for Statistical Computing: Vienna, Austria, 2015. Available online: http://www.R-project.org/ (accessed on 5 March 2014).

17. Asadian, Y.; Weiler, M. A New Approach in Measuring Rainfall Interception by Urban Trees in Coastal British Columbia. Water Qual. Res. J. Can. 2009, 44, 16-25.

18. Ilek, A.; Kucza, J. Hydrological properties of bark of selected forest tree species. Part I: The coefficient of development of the interception surface of bark. Trees 2014, 28, 831-839, doi:10.1007/s00468-014-0995-0.

19. Calder, I.; Hall, R.; Rosier, P.; Bastable, H.; Prasanna, K.T. Dependence of rainfall interception on drop size: 2. Experimental determination of the wetting functions and two-layer stochastic model parameters for five tropical tree species. J. Hydrol. 1996, 185, 379-388, doi:10.1016/0022-1694(95)02999-0.

20. Frasson, R.; Krajewski, W. Characterization of the drop-size distribution and velocity-diameter relation of the throughfall under the maize canopy. Agric. For. Meteorol. 2011, 151, 1244-1251, doi:10.1016/j.agrformet.2011.05.001.

(C) 2017 by the authors; licensee MDPI, Basel, Switzerland. This article is an open access article distributed under the terms and conditions of the Creative Commons by Attribution (CC-BY) license (http://creativecommons.org/licenses/by/4.0/). 